\title{
CONSTRUCTION OF FUZZY C CONTROL CHARTS BASED ON FUZZY RULE METHOD
}

\author{
Sevil ŞENTÜRK* \\ Deparment of Statistics, Faculty of Science, Anadolu University, Eskişehir, Turkey
}

\begin{abstract}
A control chart is a tool for representing and to monitoring a process. A control chart also detects shifts in a process and abnormal conditions in a process. If a process is monitored by c control charts, c control charts may not be applicable due to the uncertainty of the attribute data. Because process requires certain information. Many papers about fuzzy control charts, which are constructed based on information techniques with type-1 fuzzy sets, exist in literature. The fuzzy c control chart based on the fuzzy rule method is constructed in this paper for the first time. The proposed control chart is applied to real world data.
\end{abstract}

Keywords: Fuzzy, Fuzzy control chart, Rule method

\section{INTRODUCTION}

Statistical process control (SPC) is a large class of methodology for evaluating and monitoring the industrial production process to determine the special causes of each variation. Control charts are the most common SPC function to represent and monitor a process. Control charts detect assignable causes and take into account corrective actions. These are the major contributions of control charts. In traditional control charts, data that comes from a process or measurement system includes mainly operator and gauge errors which assume a crisp value. But this data includes "uncertainty" or "vagueness", because the data are collected by operators. Also, uncertainty arises in real life applications too. In this situation, fuzzy control charts are useful tools for monitoring the process.

There are some papers on fuzzy variable control charts and their applications. Rowlands and Wang [1] El-Shal and Morris [2] Zarandi et al [3] Erginel [4] Şentürk and Erginel [5], Şentürk [6], Erginel et al [7]. There are some publications on fuzzy attribute control charts and their applications in literature: Raz and Wang [8] Wang and Raz [9]. Kanagawa et al. [10] Gülbay et al [11] Gülbay and Kahraman [12] Gülbay and Kahraman [13] Şentürk et al [14] showed a theoretical structure for fuzzy control charts with applications.

Additionally, many researchers studied "fuzzy rule based method" to construct their fuzzy control charts. Kaya and Kahraman [15] proposed firstly the fuzzy rule method for evaluating the fuzzy control charts in their paper. Their method is based on some rules which define all possible patterns of a process. Also, they applied the suggested method for fuzzy $\tilde{\bar{X}}-\tilde{R}$ control charts by using a symmetric triangular fuzzy number. Erginel [16] developed a fuzzy p control chart based on both constant sample size and variable sample size and a fuzzy np control chart using decision rules. Therefore, rather in control and rather out of control decisions can be considered when in monitoring the process. Khademi and Amırzadeh [17] proposed a direct fuzzy approach to fuzzy $\tilde{\bar{X}}-\tilde{R}$ control charts by using a nonsymmetrical fuzzy number. They defined fuzzy unnatural pattern rules based on the fuzzification of the crisp rules. 
Modelling the fuzzy control charts approach contributes to more a accurate way of monitoring and evaluating the process because it takes into account of the imprecision of the membership function of the data. The control charts based on the fuzzy rule method in the literature were constructed only for $\tilde{\bar{X}}-\tilde{R}$ control charts and only for $\mathrm{p}$-np control charts. The novelty of this study is firstly to present a fuzzy rule c control chart based on decision rules for the process of state conditions. The proposed fuzzy rule c control chart abstains from some well-known defuzzification methods such as fuzzy mean, fuzzy mode, fuzzy midrange and fuzzy median. In addition, the fuzzy rule c control chart based on decision rules is implemented with real world data.

This paper is summarized as follows: Theoretical structure of Fuzzy Rule $\widetilde{c}$-Control Chart is given in section two. The third section is the application section. Also, a conclusion is presented in the fourth section.

\section{FUZZY RULE $\tilde{c}$-CONTROL CHART}

The quality characteristic is represented as a qualitative form. Attribute control charts are used to evaluate the process for example, $\mathrm{p}$ (fraction of nonconforming), $\mathrm{np}$ (nonconforming units), $\mathrm{c}$ (number of nonconformities) and $\mathrm{u}$ (nonconformities per unit) control charts. The classical c-control chart limits proposed by Shewhart are given in the following equations [18]. A control chart for nonconformities with 3-sigma limits is defined as follows.

$$
\begin{aligned}
& U C L_{c}=c+3 \sqrt{c} \\
& C L_{c}=c \\
& L C L_{c}=c-3 \sqrt{c}
\end{aligned}
$$

where UCL is the upper control limit, CL is the center line and LCL is the lower control limit of c control chart.

If $\mathrm{c}$ is not known from the population, $\mathrm{c}$ can be estimated from the sample, like;

and

$$
E[c]=\bar{c}
$$

$$
\bar{c}=\frac{\sum_{i=1}^{m} c_{i}}{m}
$$

where the expected value of $c$ equals to the mean of the nonconformities in sample.

\subsection{Fuzzy Rules $\tilde{c}$-Control Chart for Triangular Fuzzy Number}

Fuzzy set theory is very helpful for dealing with the kind of vagueness of human thought and language found in a Statistical process control. In this study, a number of nonconformities will be expressed using triangular fuzzy numbers (TFN). Let $U$ be the universe of discourse, $U=[0, u]$. The triangular fuzzy number is defined as $\tilde{A}=\left(\alpha_{m} ; \alpha_{l} ; \alpha_{r}\right)$ also is formulated;

$$
\mu_{\tilde{A}}(x)=\left\{\begin{array}{cc}
0 & x \leq \alpha_{m}-\alpha_{l} \\
1+\frac{x-\alpha_{m}}{\alpha_{l}} & \alpha_{m}-\alpha_{l} \leq x \leq \alpha_{m} \\
1-\frac{x-\alpha_{m}}{\alpha_{r}} & \alpha_{m} \leq x \leq \alpha_{m}+\alpha_{r} \\
0 & x \geq \alpha_{m}+\alpha_{r}
\end{array}\right\}
$$


where $\alpha_{m}$ is the center (mode) ; $\alpha_{l}$ is left spread ; $\alpha_{r}$ is right spread.

The demonstration of triangular fuzzy numbers will be as. $\tilde{A}=\left(\alpha_{m}-\alpha_{l} ; \alpha_{m} ; \alpha_{m}+\alpha_{r}\right)=\left(a_{l}, a_{m}, a_{r}\right)$ and it is shown in Figure 1 [19].

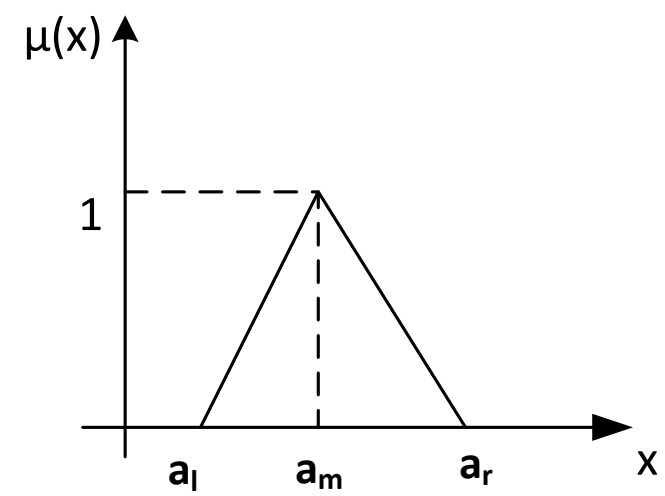

Figure 1. Representation of a sample by triangular fuzzy numbers TFN case

Fuzzy numbers $\left(a_{l}, a_{m}, a_{r}\right)$ are represented as $\left(c_{a_{l j}}, c_{a_{m j}}, c_{a_{r j}}\right)$ for each fuzzy observation on the number of nonconformities control chart. The center line of number of nonconformities control chart $C \tilde{L}$, is mean of fuzzy samples, and it is shown as $\left(\bar{c}_{a_{l}}, \bar{c}_{a_{m}}, \bar{c}_{a_{r}}\right)$ are the fuzzy averages of the number of nonconformities.

where: $j=1,2, \ldots, m$

$$
\bar{c}_{a_{l}}=\frac{\sum c_{a_{l_{j}}}}{m}, \bar{c}_{a_{m}}=\frac{\sum c_{a_{m_{j}}}}{m}, \bar{c}_{a_{r}}=\frac{\sum c_{a_{r j}}}{m}
$$

By considering the formulations of c-control limits and fuzzy numbers based on triangular membership functions, the fuzzy center line and the fuzzy upper and fuzzy lower limits of the fuzzy rule $\tilde{c}$-control chart are given as follows:

$$
\begin{aligned}
& \left(U \tilde{C} L_{c_{a_{l}}}, U \tilde{C} L_{c_{a_{m}}}, U \tilde{C} L_{c_{a_{r}}}\right)=\left(\bar{c}_{a_{l}}+3 \sqrt{\bar{c}_{a_{l}}}, \bar{c}_{a_{m}}+3 \sqrt{\bar{c}_{a_{m}}}, \bar{c}_{a_{r}}+3 \sqrt{\bar{c}_{a_{r}}}\right) \\
& \left(\tilde{C} L_{c_{a_{l}}}, \tilde{C} L_{c_{a_{m}}}, \tilde{C} L_{c_{a_{r}}}\right)=\left(\bar{c}_{a_{l}}, \bar{c}_{a_{m}}, \bar{c}_{a_{r}}\right) \\
& \left(L \tilde{C} L_{c_{a_{l}}}, L \tilde{C} L_{c_{a_{m}}}, L \tilde{C} L_{c_{a_{r}}}\right)=\left(\bar{c}_{a_{l}}-3 \sqrt{\bar{c}_{a_{r}}}, \bar{c}_{a_{m}}-3 \sqrt{\bar{c}_{a_{m}}}, \bar{c}_{a_{r}}-3 \sqrt{\bar{c}_{a_{l}}}\right)
\end{aligned}
$$

The fuzzy control limits are defined for a fuzzy rule $\tilde{c}$-control chart for a TFN case. Also this study represented the process control decision rules for a fuzzy $\tilde{c}$-control chart. The rule method is based on rules that do not require any transformation techniques. These rules are detailed for the TFN case, and three rules are determined to control a process.

Rule -1 for fuzzy $\tilde{c}$-control chart: Rule-1 consider the cases in which the fuzzy number of nonconformities lies absolutely between the fuzzy control limits or outside the fuzzy control limits, This situation is shown in Figure 2.

$$
\text { Processcontrolstate }=\left\{\begin{array}{lll}
\text { in control } & \text { if } c_{a_{r}}<U \tilde{C} L_{c_{a_{l}}} \wedge c_{a_{l}}>L \tilde{C} L_{c_{a_{r}}} \\
\text { out of control if } c_{a_{l}}>U \tilde{C} L_{c_{a_{r}}} \vee c_{a_{r}}<L \tilde{C} L_{c_{a_{l}}}
\end{array}\right\}
$$




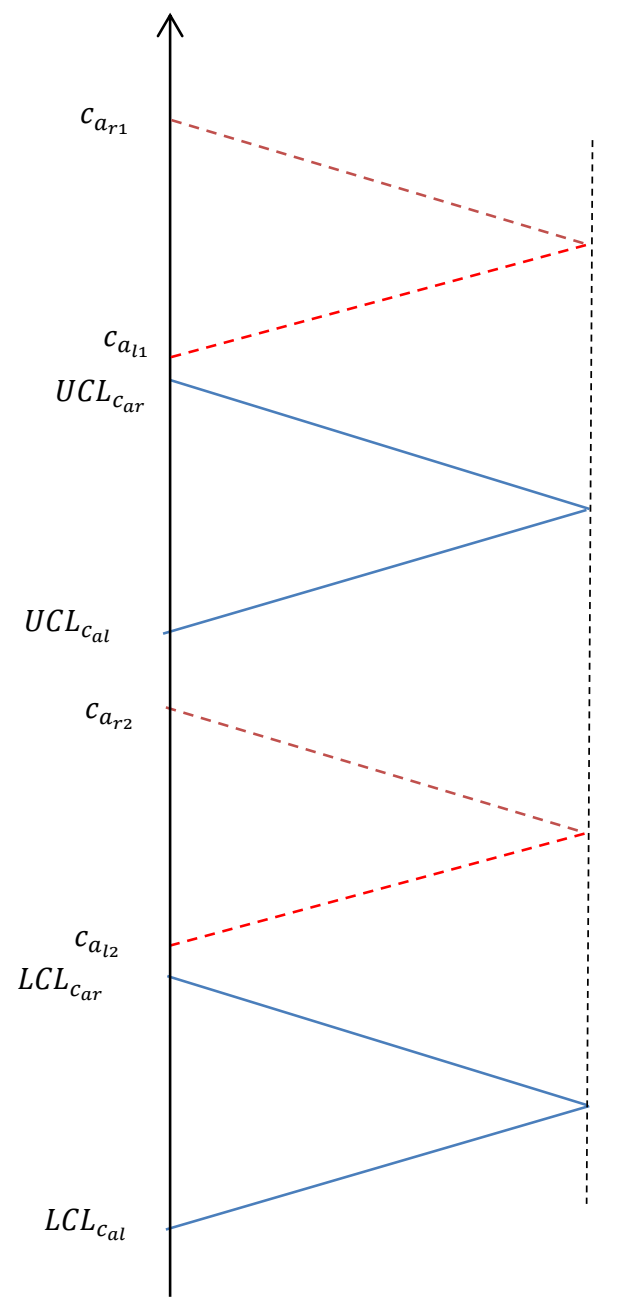

Figure 2. Rule -1 for a fuzzy $\tilde{c}$-control chart for a TFN case

Rule-2 for fuzzy $\tilde{c}$-control chart: Rule 2 evaluates the case in which the fuzzy number of nonconformities is partially included by either control limit as shown in Figure 3. If the percentage area of a number of nonconformities that remains inside the fuzzy control limits is equal to or greater than a predefined acceptable percentage $\left(\beta^{*}\right)$, then the process can be accepted as 'process rather in control'; otherwise it can be stated as 'process rather out of control'.

$$
\begin{aligned}
& \text { Processcontrol state }=\left\{\begin{array}{l}
\text { Rather in control } \\
\text { Rather out of control } \beta \geq \beta^{*}
\end{array}\right\} \\
& \beta=\left\{\begin{array}{l}
1-\frac{c_{a_{r}}-U \tilde{C} L_{c_{a_{l}}}}{c_{a_{r}}-c_{a_{l}}} \text { if } c_{a_{r}}>U \tilde{C} L_{c_{a_{l}}} \wedge c_{a_{l}}<U \tilde{C} L_{c_{a_{l}}} \\
1-\frac{\tilde{C} L_{c_{a_{r}}}-c_{a_{l}}}{c_{a_{r}}-c_{a_{l}}} \text { if } c_{a_{l}}<L \tilde{C} L_{c_{a_{r}}} \wedge c_{a_{r}}>L \tilde{C} L_{c_{a_{r}}}
\end{array}\right.
\end{aligned}
$$


Şentürk/Anadolu Univ. J. of Sci. and Technology A-Appl. Sci. and Eng. 18 (3)-2017

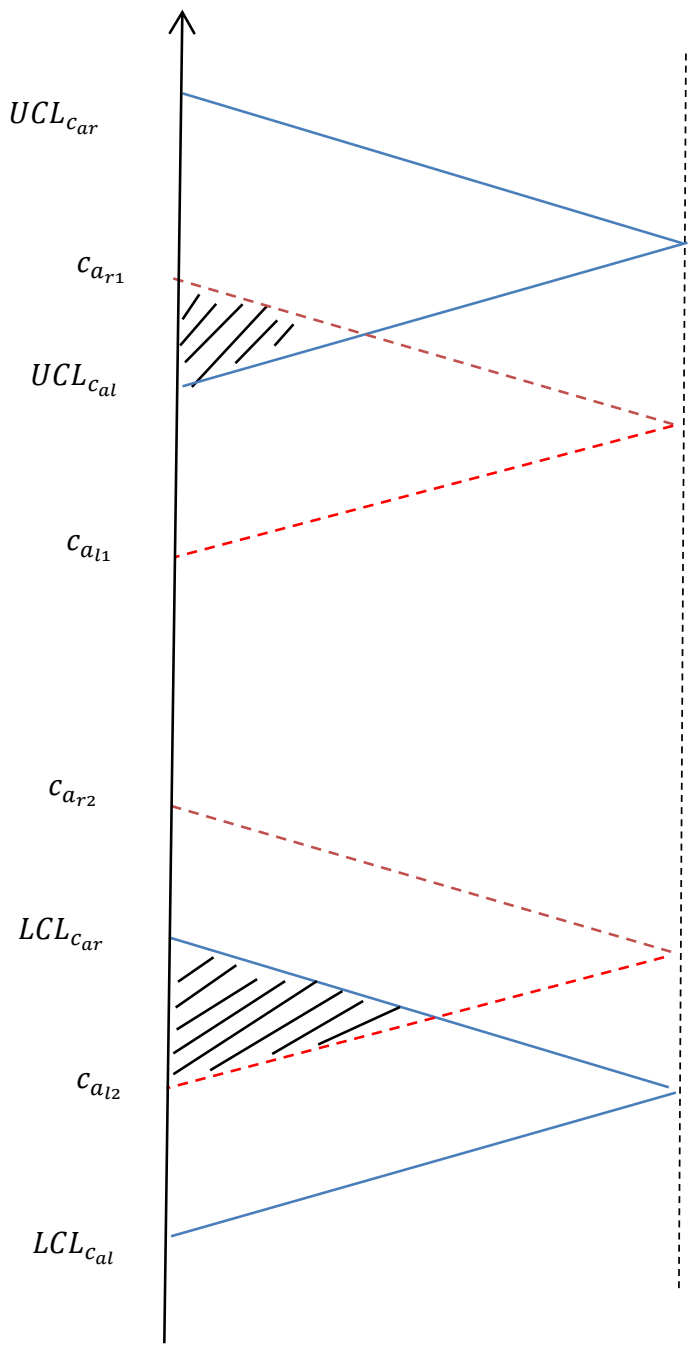

Figure 3. Rule -2 for a fuzzy $\tilde{c}$-control chart for a TFN case

Rule -3 for fuzzy $\tilde{c}$-control chart: Rule 3 analyses of the case in which the fuzzy number of nonconformities that closes the outside to either of the control limits is a partially included corresponding control limit as shown in Figure 4.

$$
\begin{gathered}
\text { Process control state }=\left\{\begin{array}{l}
\text { Rather in control } \quad \text { if } \beta \geq \beta^{*} \\
\text { Rather out of control } \quad \text { if } \beta<\beta^{*}
\end{array}\right\} \\
\beta=\left\{\begin{array}{l}
1-\frac{c_{a_{r}}-U \tilde{C} L_{c_{a_{r}}}}{c_{a_{r}}-c_{a_{l}}} \text { if } c_{a_{r}}>U \tilde{C} L_{c_{c_{r}}} \wedge c_{a_{l}}<U \tilde{C} L_{c_{a_{r}}} \\
1-\frac{c_{a_{r}}-L \tilde{C} L_{a_{a_{r}}}}{c_{a_{r}}-c_{a_{l}}} \text { if } c_{a_{l}}<L \tilde{C} L_{c_{a_{r}}} \wedge c_{a_{r}}>L \tilde{C} L_{c_{a_{r}}}
\end{array}\right.
\end{gathered}
$$




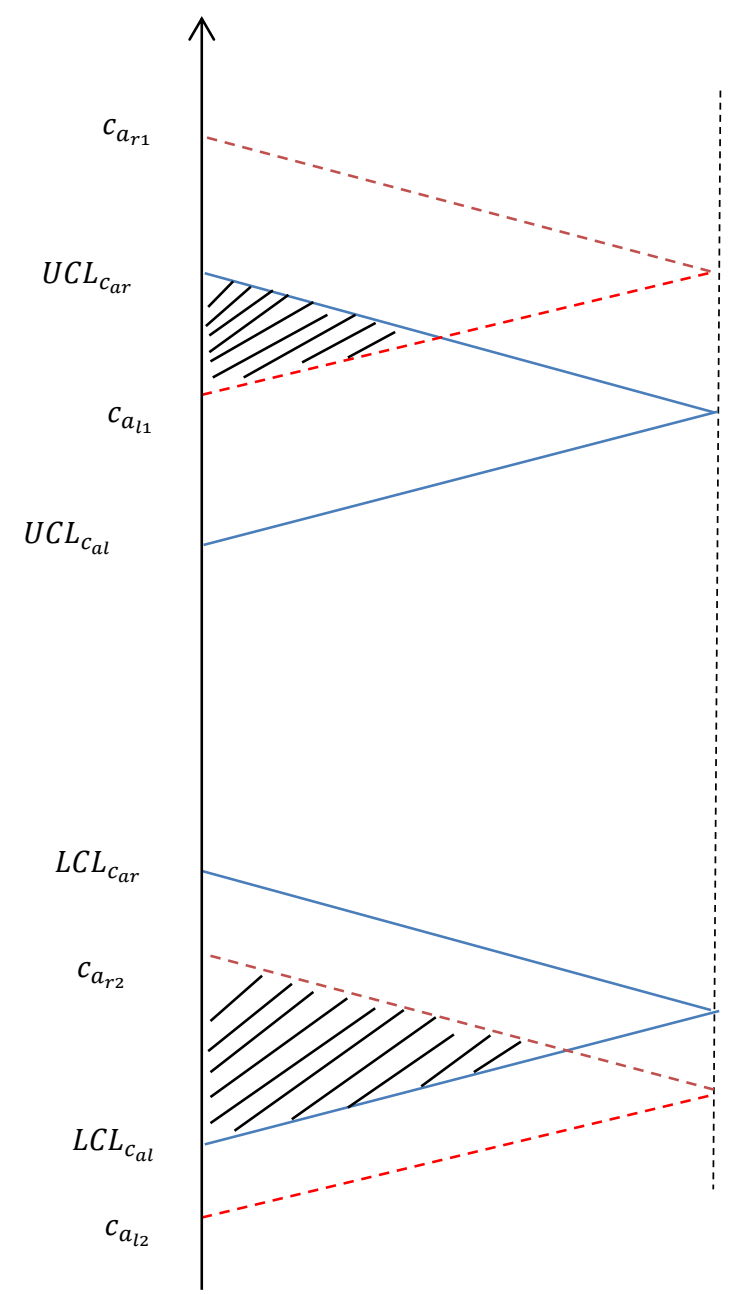

Figure 4. Rule 3 for a fuzzy $\tilde{c}$-control chart for a TFN case

\section{APPLICATION}

In this section, a fuzzy rule $\tilde{c}$-control chart application is made on an incorporated company which serves as an armature supplier in TURKEY. The values are obtained from products with a burr defect consisting of samples of 60 units in 24 periods. While collecting data from the process, some uncertainty or vagueness arises from the process or measurement system. These uncertainties are based on the process and measurement system, which can lead to some difficulties in obtaining crisp values from the process. In this situation, fuzzy control charts are useful tools for evaluating fuzzy data and fuzzy set theory specifically addressing the development of concepts and techniques for dealing with sources of uncertainty or imprecision. In this application, the fuzzy number of nonconformities are modeled with a fuzzy rule $\tilde{c}$-control chart using triangular fuzzy numbers. Collected fuzzy data are shown in Table 1 as triangular fuzzy numbers. 
Şentürk/Anadolu Univ. J. of Sci. and Technology A-Appl. Sci. and Eng. 18 (3)-2017

Table 1.Triangular fuzzy numbers for fuzzy rule $\tilde{c}$-control chart

\begin{tabular}{|c|c|c|c|}
\hline Sample & $c_{a_{l}}$ & $c_{a_{m}}$ & $c_{a_{r}}$ \\
\hline 1 & 2 & 3 & 3 \\
\hline 2 & 3 & 5 & 6 \\
\hline 3 & 2 & 4 & 5 \\
\hline 4 & 1 & 2 & 4 \\
\hline 5 & 1 & 2 & 3 \\
\hline 6 & 1 & 2 & 2 \\
\hline 7 & 1 & 3 & 5 \\
\hline 8 & 1 & 2 & 3 \\
\hline 9 & 1 & 2 & 4 \\
\hline 10 & 2 & 3 & 5 \\
\hline 11 & 1 & 3 & 4 \\
\hline 12 & 4 & 5 & 6 \\
\hline 13 & 3 & 4 & 5 \\
\hline 14 & 2 & 4 & 6 \\
\hline 15 & 1 & 5 & 7 \\
\hline 16 & 2 & 3 & 4 \\
\hline 17 & 1 & 4 & 6 \\
\hline 18 & 3 & 6 & 9 \\
\hline
\end{tabular}

$$
\bar{c}_{a_{l}}=1.78 \quad \bar{c}_{a_{m}}=3.44 \quad \bar{c}_{a_{r}}=4.83
$$

The fuzzy upper and lower control limits and fuzzy center line of the fuzzy $\tilde{c}$-control chart are calculated by using $\operatorname{Eg}(6-8)$ and given in the following equations.

$$
\begin{aligned}
\left(U \tilde{C} L_{c_{a_{l}}}, U \tilde{C} L_{c_{a_{m}}}, U \tilde{C} L_{c_{a_{r}}}\right)= & \left(\bar{c}_{a_{l}}+3 \sqrt{\bar{c}_{a_{l}}}, \bar{c}_{a_{m}}+3 \sqrt{\bar{c}_{a_{m}}}, \bar{c}_{a_{r}}+3 \sqrt{\bar{c}_{a_{r}}}\right) \\
& =(1.78+3 \sqrt{1.78}, 3.44+3 \sqrt{3.44}, 4.83+3 \sqrt{4.83}) \\
& =(5.77,8.99,11.4) \\
\left(\tilde{C} L_{c_{a_{l}}}, \tilde{C} L_{c_{a_{m}}}, \tilde{C} L_{c_{a_{r}}}\right)= & \left(\bar{c}_{a_{l}}, \bar{c}_{a_{m}}, \bar{c}_{a_{r}}\right)=(1.78,3.44,4.83) \\
\left(L \tilde{C} L_{c_{a_{l}}}, L \tilde{C} L_{c_{a_{m}}}, L \tilde{C} L_{c_{a_{r}}}\right) & =\left(\bar{c}_{a_{l}}-3 \sqrt{\bar{c}_{a_{r}}}, \bar{c}_{a_{m}}-3 \sqrt{\bar{c}_{a_{m}}}, \bar{c}_{a_{r}}-3 \sqrt{\bar{c}_{a_{l}}}\right) \\
& =(1.78-3 \sqrt{4.83}, 3.44-3 \sqrt{3.44}, 4.83-3 \sqrt{1.78}) \\
& =(-4.79,-2.11,0.84)
\end{aligned}
$$

The fuzzy upper and lower control limits and fuzzy center line of the fuzzy $\tilde{c}$-control chart are given in Table 2.Additionally, the process conditions are determined in accordance with the defined rules are showed in Table 2. 
Table 2. Fuzzy rule $\tilde{c}$-control chart limits and process condition

\begin{tabular}{|c|c|c|c|c|}
\hline Sample & $\left(U \tilde{C} L_{c_{a_{l}}}, U \tilde{C} L_{c_{a_{m}}}, U \tilde{C} L_{c_{a_{r}}}\right)$ & $\left(\tilde{C} L_{c_{a_{l}}}, \tilde{C} L_{c_{a_{m}}}, \tilde{C} L_{c_{a_{r}}}\right)$ & $\left(L \tilde{C} L_{c_{a_{l}}}, L \tilde{C} L_{c_{a_{m}}}, L \tilde{C} L_{c_{a_{r}}}\right) \begin{array}{l}\text { Process } \\
\text { condition }\end{array}$ \\
\hline 1 & $(5.77,8.99,11.4)$ & $(1.78,3.44,4.83)$ & $(-4.79,-2.11,0.84)$ & in control \\
\hline 2 & $(5.77,8.99,11.4)$ & $(1.78,3.44,4.83)$ & $(-4.79,-2.11,0.84)$ & rather in control \\
\hline 3 & $(5.77,8.99,11.4)$ & $(1.78,3.44,4.83)$ & $(-4.79,-2.11,0.84)$ & in control \\
\hline 4 & $(5.77,8.99,11.4)$ & $(1.78,3.44,4.83)$ & $(-4.79,-2.11,0.84)$ & in control \\
\hline 5 & $(5.77,8.99,11.4)$ & $(1.78,3.44,4.83)$ & $(-4.79,-2.11,0.84)$ & in control \\
\hline 6 & $(5.77,8.99,11.4)$ & $(1.78,3.44,4.83)$ & $(-4.79,-2.11,0.84)$ & in control \\
\hline 7 & $(5.77,8.99,11.4)$ & $(1.78,3.44,4.83)$ & $(-4.79,-2.11,0.84)$ & in control \\
\hline 8 & $(5.77,8.99,11.4)$ & $(1.78,3.44,4.83)$ & $(-4.79,-2.11,0.84)$ & in control \\
\hline 9 & $(5.77,8.99,11.4)$ & $(1.78,3.44,4.83)$ & $(-4.79,-2.11,0.84)$ & in control \\
\hline 10 & $(5.77,8.99,11.4)$ & $(1.78,3.44,4.83)$ & $(-4.79,-2.11,0.84)$ & in control \\
\hline 11 & $(5.77,8.99,11.4)$ & $(1.78,3.44,4.83)$ & $(-4.79,-2.11,0.84)$ & in control \\
\hline 12 & $(5.77,8.99,11.4)$ & $(1.78,3.44,4.83)$ & $(-4.79,-2.11,0.84)$ & rather in control \\
\hline 13 & $(5.77,8.99,11.4)$ & $(1.78,3.44,4.83)$ & $(-4.79,-2.11,0.84)$ & in control \\
\hline 14 & $(5.77,8.99,11.4)$ & $(1.78,3.44,4.83)$ & $(-4.79,-2.11,0.84)$ & rather in control \\
\hline 15 & $(5.77,8.99,11.4)$ & $(1.78,3.44,4.83)$ & $(-4.79,-2.11,0.84)$ & rather in control \\
\hline 16 & $(5.77,8.99,11.4)$ & $(1.78,3.44,4.83)$ & $(-4.79,-2.11,0.84)$ & in control \\
\hline 17 & $(5.77,8.99,11.4)$ & $(1.78,3.44,4.83)$ & $(-4.79,-2.11,0.84)$ & rather in control \\
\hline 18 & $(5.77,8.99,11.4)$ & $(1.78,3.44,4.83)$ & $(-4.79,-2.11,0.84)$ & rather in control \\
\hline
\end{tabular}

The process conditions are determined by the defined rules and are given in Table 2. According to the Table 2, twelve point are "in control". The situation is obtained by using Rule 1 (comparison $\left.c_{a_{r}}<U \tilde{C} L_{c_{a_{l}}} \wedge c_{a_{l}}>L \tilde{C} L_{c_{a_{r}}}\right)$. Also, 6 points are in the "rather in control" situation. The condition of the process is gathered by using the first condition of Rule 2 . $\left(\beta=1-\frac{c_{a_{r}}-U \tilde{C} L_{c_{a_{l}}}}{c_{a_{r}}-c_{a_{l}}}\right.$ if $\left.c_{a_{r}}>U \tilde{C} L_{c_{a_{l}}} \wedge c_{a_{l}}<U \tilde{C} L_{c_{a_{l}}}\right)$. In using these rules, $\beta^{*}$ is assumed as 0.60.

If $\beta$ is greater than $\beta^{*}$, the process is "rather in control" at this point. Thus, for the $2^{\text {th }}$ point, $12^{\text {th }}$ point, $14^{\text {th }}$ point, $15^{\text {th }}$ point, $17^{\text {th }}$ point and $18^{\text {th }}$ point are "rather in control". Therefore, the process should be reconsidered.

\section{CONCLUSION}

If the process is monitored by Shewhart's control charts, than these traditional control charts assume that the data has crisp values. However, the process is not always crisp. Uncertainty comes from the measurement system or environmental conditions. Thus fuzzy control charts are inevitable tools for monitoring the process. In the literature, fuzzy control charts are used to evaluate the process by using transformation techniques. In these situations, decisions include only "in control" or "out of control". However, "rather in control" and "rather out of control" decisions can be considered for process decisions in the fuzzy control chart based on the rule method. Also, the operator can be included in the process decision by changing the beta level. The fuzzy c control chart based on fuzzy rule method is constructed for the first time in this paper and is applied to real world data. In further research, fuzzy c control charts can be modelled by using interval type- 2 fuzzy sets theory when the data are an interval type-2 fuzzy number. 


\section{REFERENCES}

[1] Rowlands H and Wang LR. An approach of fuzzy logic evaluation and control in SPC, Quality Reliability Engineering Intelligent ,16, 2000, 91-98.

[2] El-Shal SM and Morris AS. A fuzzy rule-based algorithm to improve the performance of statistical process control in quality systems, Journal of Intelligent Fuzzy Systems, 9, 2000, 207-223.

[3] Zarandi MHF, Alaeddini A and Turksen IB. A hybrid fuzzy adaptive sampling - Run rules for Shewhart control charts, Information Sciences, 178, 2008, 1152-1170.

[4] Erginel N. Fuzzy individual and moving range control charts with $\alpha$-cuts, Journal of Intelligent \& Fuzzy Systems, 19, 2008, 373-383.

[5] Şentürk S and Erginel N. Development of fuzzy $\tilde{\bar{X}}-\tilde{R}$ and $\tilde{\bar{X}}-\tilde{S}$ control charts using $\alpha$-cuts, Information Sciences, 179, 2009, 1542-1551.

[6] Şentürk S. Fuzzy Regression Control Chart Based on $\alpha$-cut Approximation, International Journal of Computational Intelligence Systems, 3(1), 2010, 123-140.

[7] Erginel N, Şentürk S, Kahraman C and Kaya İ. Evaluating the packing process in food industry using fuzzy and control charts, International Journal of Computational Intelligence Systems, 4, 2011, 509-520.

[8] Raz T and Wang JH. Probabilistic and memberships approaches in the construction of control chart for linguistic data, Production Planning and Control, 1, 1990, 147.

[9] Wang JH and Raz T. On the construction of control charts using linguistic variables, Intelligent Journal of Production Research, 28,1990, 477-487.

[10] Kanagawa A, Tamaki F and Ohta $\mathrm{H}$. Control charts for process average and variability based on linguistic data, Intelligent Journal of Production Research, 31(4),1993, 913-922.

[11] Gülbay M, Kahraman C and Ruan D. $\alpha$-cut Fuzzy control charts for linguistic data, International Journal of Intelligent Systems 19, 2004, 1173-1196.

[12] Gülbay M and Kahraman C. Development of fuzzy process control charts and fuzzy unnatural pattern analyses, Computational Statistics and Data Analysis, 51, 2006a, 434-451.

[13] Gülbay M and Kahraman C. An alternative approach to fuzzy control charts: Direct fuzzy approach, Information Sciences, 77 (6), 2006b, 1463-1480.

[14] Şentürk S, Erginel N, Kaya İ and Kahraman C. Design of Fuzzy $\tilde{u}$ Control Chart, Journal of Multiple Valued- Logic and Soft Computing, 2011, 459-473.

[15] Kaya İ and Kahraman C. Process capability analyses based on fuzzy measurement and fuzzy control charts, Expert systems with applications, 38, 2011, 3172-3184.

[16] Erginel N. Fuzzy Rule Based p-np control charts, Journal of Intelligent Fuzzy Systems, 27, 2014, $159-171$. 
Şentürk / Anadolu Univ. J. of Sci. and Technology A-Appl. Sci. and Eng. 18 (3)- 2017

[17] Khademi M and Amırzadeh V. Fuzzy rules for fuzzy and R Control charts, Iranian Journal of Fuzzy systems, 11(5), 2014, 55-56.

[18] Montgomery DC. Introduction to Statistical Quality Control, John Wiley and Sons. Inc, 1991, 351.

[19] Chen SJ, Hwang CL and Hwang FP. Fuzzy multiple attribute decision making methods and applications, Springer-Verlag, Berlin 1992 . 